\title{
Performance Measurement in the UK Construction Industry and its Role in Supporting the Application of Lean Construction Concepts
}

Saad Sarhan and Andrew Fox, (University of Plymouth, UK)

\begin{abstract}
Performance measurement has received substantial attention from researchers and the construction industry over the past two decades. This study sought to assess UK practitioners' awareness of the importance of the use of appropriate performance measures and its role in supporting the application of Lean Construction (LC) concepts. To enable the study to achieve its objectives, a review of a range of measurements developed to evaluate project performance including those devoted to support LC efforts was conducted. subsequently a questionnaire survey was developed and sent to 198 professionals in the UK construction industry as well as a small sample of academics with an interest in LC. Results indicated that although practitioners recognise the importance of the selection of nonfinancial performance measures, it has not been properly and widely implemented. The study identified the most common techniques used by UK construction organisations for performance measurement, and ranked a number of non-financial key performance indicators as significant. Some professed to have embraced the Last Planner System methodology as a means for performance measurement and organisational learning, while further questioning suggested otherwise. It was also suggested that substance thinking amongst professionals could be a significant hidden barrier that militates against the successful implementation of LC.
\end{abstract}

Keywords: Construction Industry, Lean Construction, Project Performance Measurement, Psychology, UK

\section{Introduction}

A growing number of companies worldwide began to recognise the benefits that could be achieved from adopting the lean construction (LC) approach (Arbulu and Zabelle, 2006). Many practitioners and academics have reported case studies where their companies were achieving some proven benefits and pockets of excellence (Alarcon et al., 2002; Swain and Mossman, 2003; Wu and Low, 2011; Andersen et al., 2012; Keiser, 2012). However, a number of studies in countries across the globe have revealed that the application of lean principles to construction has not been successful due to a number of critical factors/barriers (Olatunji, 2008; Senaratne and Wijesiri, 2008; Abdullah et al., 2009; Mossman, 2009a). One of these factors is the failure to use appropriate process performance measurement systems (PMS); which is crucial to support the implementation of LC (Sarhan and Fox, 2012).

Although process performance measurements have received substantial attention from academic researchers over the past two decades, the construction industry still has a preference for measureing performance in terms of time and cost (Bowen et al., 2002; Forbes et al., 2002). These traditional (results-based) performance preferences measured in projects, specifically costs and schedule, are not appropriate for continuous improvement because they are not effective in identifying the root-causes of quality and productivity losses (Alarcon and Serpell, 1996). Despite this fact, there are very few, if any, studies that have sought to explore and understand the reasons why professionals and managers in the construction industry still have a tendency to measure performance in terms of time, cost and meeting code, as opposed to process performance measures (e.g. cycle time, Rework, 
waste). A series of ontological work by Rooke et al. (2003; 2004; 2007) strongly suggests that the overreliance of managers and professionals on objects rather than processes as the key to understanding and communicating about construction projects, presents a barrier to learning flow-based solutions. Based on a review of a range of measurements developed to evaluate project performance including those devoted to support lean construction efforts, as well as a systematic consideration to the series of work done by Rooke et al $(2003 ; 2004$; 2007), this research carried out a survey among UK professionals to assess their awareness of the importance of the use/selection of appropriate performance measures, crucial to support the implementation of the LC approach.

\section{Lean Thinking in Construction}

Lean thinking is a philosophy based on the concepts of lean production. The first consideration of the ideas of lean production for use within construction is attributed to Koskela (1992) (Garnett et al., 1998; Mossman, 2009a). Koskela (1992) formulated the transformation-flow-value generation model of production, known as the TFV theory of production, which could lead to improved performance when applied to construction. This seminal technical-report (Koskela, 1992) proposed the need to review construction production as a combination of conversion and flow processes to remove waste, when traditional thinking of construction was only focusing on conversion activities and ignoring flow and value considerations (Garnett et al., 1998; Senaratne and Wijesiri, 2008). There are eight types of waste which are commonly agreed on by researchers: Transportation, Inventory, Motion, Waiting, Over-Production, Over-Processing, Defects, Skills Misuse (Terry and Smith, 2011). Consequently, many researchers emphasised the importance of the use of appropriate performance measurement systems, which can give early warnings and identify problems before they occur, to support the successful implementation of lean construction (Lantelme and Formoso, 2000; Alarcón et al., 2001; Leong and Tilley, 2008; Sarhan and Fox, 2012).

\section{Performance Measurement Systems}

The use of simple and well-designed performance measurement systems (PMSs) is essential for supporting the implementation of business strategies, such as the application of LC concepts within construction organisations. That is because performance measurement provides the information required for process control and makes it possible to set up challenging goals (Lantelme and Formoso, 2000; Moon et al., 2007). Neely et al. (1996) define performance measurement as "the process of quantifying effectiveness and efficiency of action ". Effectiveness is the extent to which a target is achieved (e.g. client satisfaction) with resources applied (Neely et al., 1996; Cheng et al., 2009). Efficiency is the evaluation of how economically the resources are utilised to meet client requirements (Neely et al., 1996).

Without the use of appropriate PMSs, it becomes very difficult for organizations to understand why poor performance continues, or how improvement could be achieved (Leong and Tilley, 2008). In addition, without PMSs managers cannot know whether they will be able to achieve their intended objectives and goals or not (Neely et al., 1996). According to Chrysostomou (2000) "to manage you must measure, if you don't you are only practising"; cited in Alarcón et al. (2001). This points out that the selection of appropriate measures has a major influence on the implementation of strategies, and is essential for the development of improvement programmes (Lantelme and Formoso, 2000).

\section{Result-Based Indicators vs. Process-Based Indicators}

Traditional performance measurement systems are based on financial measures (Lantelme and Formoso, 2000; Suwignjo et al., 2000). These financial measures are result-oriented performance indicators, and have been strongly criticised by many researchers (Alarcón et al., 2001; Mitropoulos and Howell, 2001; Takim and Akintoye 2002; Costa et al. 2004; Moon et al., 2007; Nudurupati et al., 2007; Leong and Tilley, 2008). That is because these

Sarhan, S and Fox, A (2013) 'Performance measurement in the UK construction industry and its role in supporting the application of lean construction concepts', Australasian Journal of Construction Economics and Building, 13 (1) 23-35 
parameters are backward focused (Lantelme and Formoso, 2000). They are not measured until project is complete; and thus the information obtained arrives too late to take any corrective actions (Alarcón and Serpell, 1996; Moon et al., 2007). As a result, these outcome based indicators cannot be used to identify barriers or problems that exist during the execution of processes. According to Alarcón et al. (2001) traditional control systems focus their attention in conversion activities and ignore flow activities; therefore nearly all non-value-adding activities become invisible.

Instead, Costa et al. (2004) recommend the use of (process-oriented) leading measures aiming to give early warnings, identify barriers and potential problems, and emphasize the need for future investigation. This recommendation is supported by Neely et al. (1996) who asserted the need to adopt formal process based approaches. It is important to use measures for tracking improvement not reporting (Terry and Smith, 2011). Likewise, Alarcón et al. (2001) emphasise that measurement alone is not enough; it is essential to analyse these indicators with the objective to detect the problems and their root causes.

\section{Key Performance Indicators (KPIs) in the UK}

There is an industry tendency to measure performance in terms of time, cost and meeting code; but very limited consideration has been subjected to client satisfaction (Forbes et al., 2002). In order to help organisations move towards best practice in response to the Egan's report (1998), the UK working groups on KPIs identified a set of non-financial parameters for benchmarking projects (Takim and Akintoye, 2002; Dawood et al., 2006). These KPls are classified into three levels, namely, headline, operational, and diagnostic (Costa et al., 2004; Nudurupati et al., 2007). Headline indicators provide a measure of the overall health of a firm. Operational Indicators bear on specific aspects of a firm's activities and should enable management to identify and focus on specific areas for improvement. Diagnostic Indicators provide information on why certain changes may have occurred in the headline or operational indicators and are useful in analysing areas for improvement in more detail (The KPI Working Group, 2000).

Despite the KPI programme, there are some problems identified in the KPIs. For instance, none of the measures mentioned could identify the performance of suppliers in a project environment (Takim and Akintoye, 2002; Costa et al., 2004). Also, there are no suggestions for performance indicators in benchmarking projects at the project selection phase, such as the analysis stage (Takim and Akintoye, 2002). For this reason, Takim and Akintoye (2002) propose that the successful construction project performance can be divided along three orientations: procurement, process, and results oriented. A similar approach was adopted by Sikka et al. (2006) who classified KPIs into three conceptual phases of a construction project: pre-construction, construction, and post-construction; as they believe that project success criteria change with time in each phase.

\section{The Balanced Scorecard}

The balanced scorecard (BSC) is a widely accepted framework (Nudurupati et al., 2007). It was constructed to complement measures of past performance with measures of the drivers of future performance (Nudurupati et al., 2007). It links an organisation's strategy through a series of perspectives to KPIs (Fraser and Kelly, 2011). According to Karanseh and Al-Dahir (2012) the BSC performance measurement model as presented by Kaplan and Norton (1992) is a business management concept that is more focussed on strategy and vision rather than control. However, it could be argued that it can be difficult and confusing to integrate between the BSC's strategic and operational level measures (Karanseh and AlDahir, 2012). 


\section{Quantitative Models for Performance Measurement Systems (QMPMS)}

QMPMSs use cognitive maps, cause and effect diagrams, tree diagrams, and the analytic hierarchy process, to quantify the effect of factors on performance (Suwignjo et al., 2000; Nudurupati et al., 2007). There are three main steps in QMPMS: (1) identifying the factors that affect performance and their relationships; (2) structuring the factors hierarchically; (3) quantifying the effect of factors on performance (Suwignjo et al., 2000; Nudurupati et al., 2007). The quantification process is carried out based on the results of a pair-wise comparison questionnaire among the factors (subjective technique).

This approach for quantifying the effects of factors on performance could be criticised because it is subjective, and it may be difficult to be applied in practices. One of the potential problems of this approach is that performance improvement usually involves identification of a large number of factors affecting performance. Consequently, the number of pairwise comparison questionnaire will be huge; and filling it in will be exhausting and time consuming (Suwignjo et al., 2000).

\section{The Last Planner System and Lean-based Process Measures}

The Last Planner System (LPS) for production control (Ballard, 2000) has been implemented in construction projects with varying levels of success, to increase the reliability of planning, improve production performance, and create a predictable workflow (Hamzeh et al., 2009). Through the LPS methodology, project teams commit to complete assigned tasks in a given week. Some LC practitioners refer to percentage plans complete (PPC) as a metric for commitment reliability. According to Forbes and Ahmed (2011) a PPC value does not measure the level of utilization of a work flow (efficiency). Instead it measures production planning effectiveness and workflow reliability. At each weekly meeting, time is given to learn and understand why certain tasks were not completed as planned in the previous week, before creating a new weekly plan to be executed. The uncompleted plans are studied and analysed to determine the barriers and root causes that affected the implementation process. The five-WHY analysis procedure could be used for identifying the root-causes of problems; and a Pareto chart could be used for ranking the barriers and reasons for noncompletion. Consequently, the information gained from the root-cause analysis would help the project teams to avoid obstacles in future work cycles, and improve the effectiveness and reliability of future work plans (Forbes and Ahmed, 2011).

Many researchers, over the last two decades, have published papers which included a wide range of process and lean-oriented performance measures for use within the constrction industry. For example, Alarcón et al. (2001) suggested a set of parameters that are lean based, and which could help companies to measure waste, cycle times and re-work in construction projects. Moon et al. (2007) proposed a set of process-oriented performance indicators which are derived from the TFV theory: reliability, efficiency and effectiveness. Leong and Tilley (2008) proposed a lean strategy to performance measurement, which aims to reduce waste in projects by measuring next customer needs. In general, the essence in these approaches is to create a measurement culture, within organisations, that will facilitate future implementations. More lean performance measures can also be found at Forbes and Ahmed (2011). However, it seems that some of these initiative lean performance measures still require further development and experimentation, in order to gain wide acceptance in the construction industry.

\section{Predominance of Results-Based Solutions in the Thinking of Professionals in Construction}

Ontological work by Rooke et al. (2003; 2004; 2007) emphasised that the most successful production management solutions are flow based ones; and that adherence to substance (results based) thinking poses a significant barrier to achieving progress in the construction industry. This suggestion is strongly supported by educational psychology work by (Itza-Ortiz

Sarhan, S and Fox, A (2013) 'Performance measurement in the UK construction industry and its role in supporting the application of lean construction concepts', Australasian Journal of Construction Economics and Building, 13 (1) 23-35 
et al., 2003) where it was observed that students in general tend to face difficulties in absorbing process-based theories, in contrast to more simply understood substance-based ones.

An example of this in the UK is the use of bills of quantity (BoQ) based on the Civil Engineering Standard Method of Measurement (CESSM). That is because there are two problems, which could lead to price variations and delivery difficulties, that exist with CESSM based bills. First, aggregating the BoQ items into self-contained construction operations is done by client representives and may not match the way the contractor intends to do the works (Hoare and Broome, 2001). The second is due to the lack of transparency in the way that prices are made up as to the contractor's assumptions about profit and quality of work (Rooke et al., 2007). In total, two methods were identified by Rooke et al. (2007) as examples of results-based thinking (CESSM and the design/construction dichotomy) while three as examples of flow-based thinking (the activity schedule, the LPS and claims planning).

\section{Research Method}

This research study aims to assess UK practitioners' understanding of the importance of the use of appropriate PMSs and its role in supporting the implementation of initiative business strategies such as lean construction. In order to achieve this aim, the following research objectives were derived:

- Conduct a literature review of a range of measurements developed to evaluate project performance including those devoted to support lean construction efforts;

- Identify the most common techniques used by construction organisations for performance measurement;

- Identify and rank the significant (most important) non-financial key performance indicators for construction organisations;

- Identify how LPS is being used within construction organisations in terms of its areas of application;

- Assess practitioners' understanding to the function of the PPC value within the LPS.

An invitation to complete a questionnaire survey was sent to 198 professional practitioners in the UK construction industry as well as a small sample of academics with an interest in LC (10 for a pilot study and 188 for the main study). Participants were selected randomly from a number of professional groups that represent most of the professional organisations involved in the UK construction industry. These groups are the Chartered Institute of Building (CIOB), Institution of Civil Engineers (ICE), Royal Institute of British Architects (RIBA), Institute of Highway Engineers (IHE), Royal Institution of Chartered Surveyors (RICS), and the Lean Construction Institution in the UK (LCI-UK). Academics formed $4 \%$ of the sample and were selected incidentally as they hold professional status and qualifications. However, their responses were not excluded from the analysis of the survey because they specialise in construction management and have wide industry experience. A total of 140 responses were received representing a response rate of $74.5 \%(S E=0.032)$. Some techniques were adopted to help the study to capture this high rate of response. These include:

- Pilot studies - Piloting is good research practice and is part of the research Plan-DoCheck-Act process (Lancaster et al., 2004).

- Both the invitation letter as well as the front cover of the questionnaire included an information sheet for the participants, which illustrated clearly what the research was about, what it involved, and ensured data protection.

- Follow ups and reminders by direct contact. Each participant of the sample was contacted individually by email.

Sarhan, S and Fox, A (2013) 'Performance measurement in the UK construction industry and its role in supporting the application of lean construction concepts', Australasian Journal of Construction Economics and Building, 13 (1) 23-35 
The distribution/mixture of the professionals and organisations involved in this study are shown in Tables 1 and 2. The largest proportion of the participants was for civil engineers (34\%). In addition, more than half of the respondents (63\%) were from practitioners holding managerial positions and with more than 10 years of experience in the industry.

\begin{tabular}{|c|c|c|c|c|c|c|c|c|c|}
\hline \multicolumn{2}{|c|}{$\begin{array}{c}\text { [1] Years of } \\
\text { experience }\end{array}$} & \multicolumn{3}{|c|}{ [2] Current role (Managerial level) } & \multicolumn{2}{c|}{ [3] Level of education } \\
\hline $0-10$ & $\begin{array}{c}10- \\
20\end{array}$ & $20+$ & $\begin{array}{c}\text { Graduate } \\
\text { Junior }\end{array}$ & $\begin{array}{c}\text { Middle } \\
\text { management }\end{array}$ & $\begin{array}{c}\text { Senior } \\
\text { management }\end{array}$ & Other & $\begin{array}{c}\text { Practical } \\
\text { qualification }\end{array}$ & $\begin{array}{c}\text { Bachelor's } \\
\text { degree }\end{array}$ & $\begin{array}{c}\text { Master's } \\
\text { Degree } \\
\text { and } \\
\text { above }\end{array}$ \\
\hline $37 \%$ & $26 \%$ & $37 \%$ & $14 \%$ & $26 \%$ & $22 \%$ & $37 \%$ & $25 \%$ & $36 \%$ & $39 \%$ \\
\hline
\end{tabular}

Table 1 Distribution of the sample in percentage (Clustering of individuals)

\begin{tabular}{|c|c|c|c|c|c|c|c|}
\hline \multicolumn{2}{|c|}{ [1] Average Annual Turnover in £ Millions } & \multicolumn{2}{|c|}{ [2] Size of organisations } & \multicolumn{2}{|c|}{ [3] Major Client } \\
\hline $1-100$ & $100-1000$ & $1000+$ & $<500$ employees & $>500$ employees & Private & Public & Both \\
\hline $40 \%$ & $31 \%$ & $29 \%$ & $46 \%$ & $54 \%$ & $14 \%$ & $26 \%$ & $60 \%$ \\
\hline
\end{tabular}

Table 2 Distribution of the sample in percentage (Clustering of organisations)

\section{Research Results and Analysis}

Techniques used by construction organisations for performance measurement A range of measurements developed to evaluate project performance were identified from literature and introduced to a question, in order to allow the study to identify the most common techniques used by construction organisations for performance measurement. The responses revealed that result-oriented KPIs are the most common technique used amongst construction organisations for performance measurement. It was also found that many organisations still rely heavily on the experience of their managers as means for performance measurement (Figure 1).

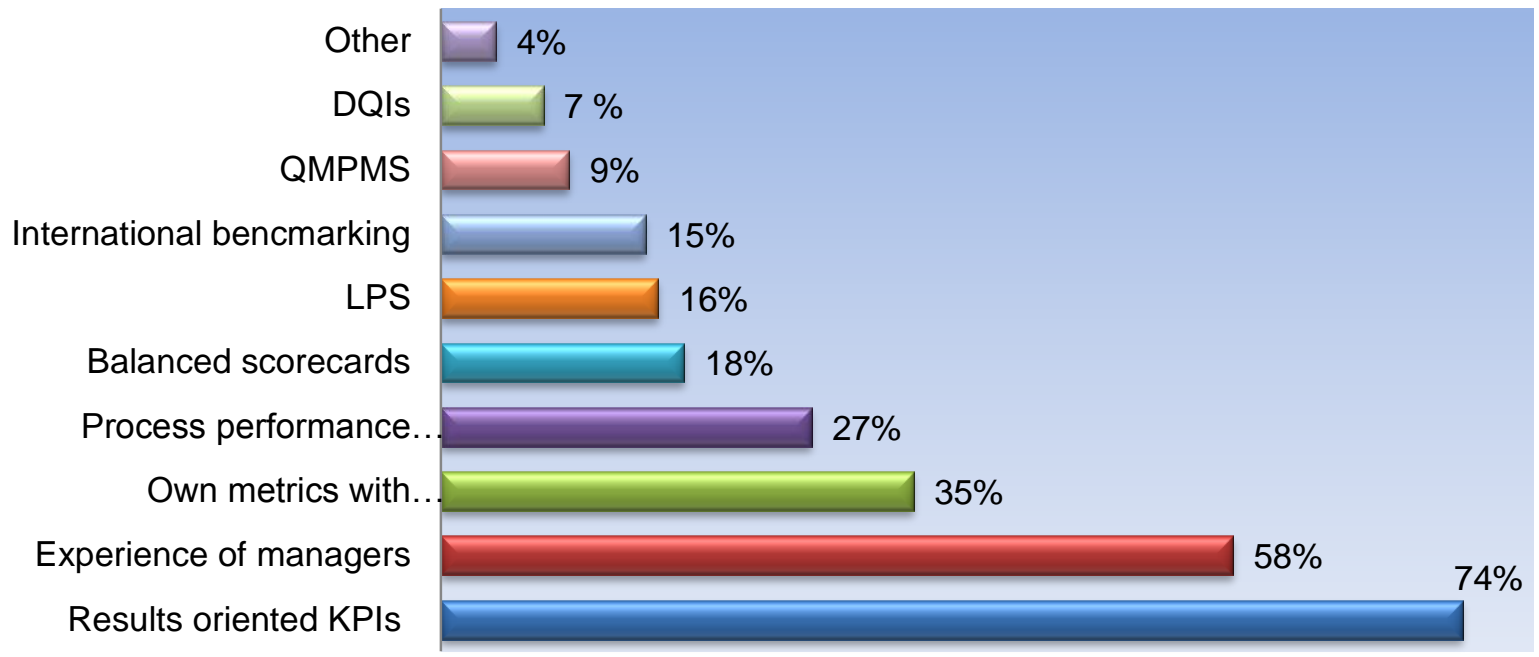

Figure 1 Techniques used by construction organisations for performance measurement

Sarhan, S and Fox, A (2013) 'Performance measurement in the UK construction industry and its role in supporting the application of lean construction concepts', Australasian Journal of Construction Economics and Building, 13 (1) 23-35 


\section{Significant Key Non-financial Performance Measures}

A question was introduced to rank and identify the significant 'non-financial' key performance indicators (leading indicators) that are appropriate for continuous improvement, according to their importance to organisations. The respondents were asked to rate the given nonfinancial performance measures on a ten-point scale to indicate the level of importance (10 being the most important and 1 being the least important). A 10-point, end-defined, scale was adopted for this question based on feedback received from pilot studies because it gives more room to the respondents for a real appreciation with the 10 possibilities. According to Cummins and Gullone (2000) " $A$ review of the literature indicates that expanding the number of choice-points beyond 5- or 7-points does not systematically damage scale reliability, yet such an increase does increase scale sensitivity".

The mean values of the given non-financial performance measures were then determined to indicate the degree of importance of these performance measures to construction organisations from the perspective of the respondents (Table 3). If the mean value scored " 8 " or above to a particular performance measure, then it would be classified as a significant performance measure. In similar research, Cheng et al.(2001), Chan et al. (2003), and Lam et al. (2007) represented the level of significance on a five-point Likert scale by a score of "4".

\begin{tabular}{|c|l|c|}
\hline Rank & Non-financial performance measures & Mean value score out of 10 \\
\hline 1 & Safety & 9.504 \\
\hline 2 & Client/customer satisfaction & 9.149 \\
\hline 3 & Quality & 8.775 \\
\hline 4 & Team Performance & 7.803 \\
\hline 5 & Productivity & 7.785 \\
\hline 6 & Functionality & 7.654 \\
\hline 7 & Planning Efficiency & 7.607 \\
\hline
\end{tabular}

Table 3 Ranking of non-financial key performance indicators according to their importance to construction organisations

Note: The shaded areas represent the significant performance measures

Table 3 shows that the mean values of safety, client satisfaction and quality exceed the cutoff point (a score of 8), and thus are considered as the significant (most important) nonfinancial KPIs for construction organisations. A reliability test was conducted for this question and Cronbach's Alpha value was found to be 0.832; which indicates a high degree of reliability, as a value $\geq 0.7$ is considered to be acceptable (Lam et al., 2007; Ab Rahman et al. 2011).

\section{Areas of Application of LPS within Construction Organisations}

A question was then added to identify how LPS is being used within organisations. Also, to determine whether organisations are aware of the full benefits of LPS and its importance in providing means for performance measurement and organisational learning, or if LPS is just seen by them as an activity scheduling tool. The respondents had the chance to choose more than one answer. More than half $(61 \%)$ of the respondents stated that the question is 'Not Applicable', while 39\% of them acknowledged that LPS is used by their organisations. Figure 2 below shows the arrangement of the different areas of application of LPS, according to their frequency of use within organisations involved in this study.

Sarhan, S and Fox, A (2013) 'Performance measurement in the UK construction industry and its role in supporting the application of lean construction concepts', Australasian Journal of Construction Economics and Building, 13 (1) 23-35 
LPS is used in your organisation for:

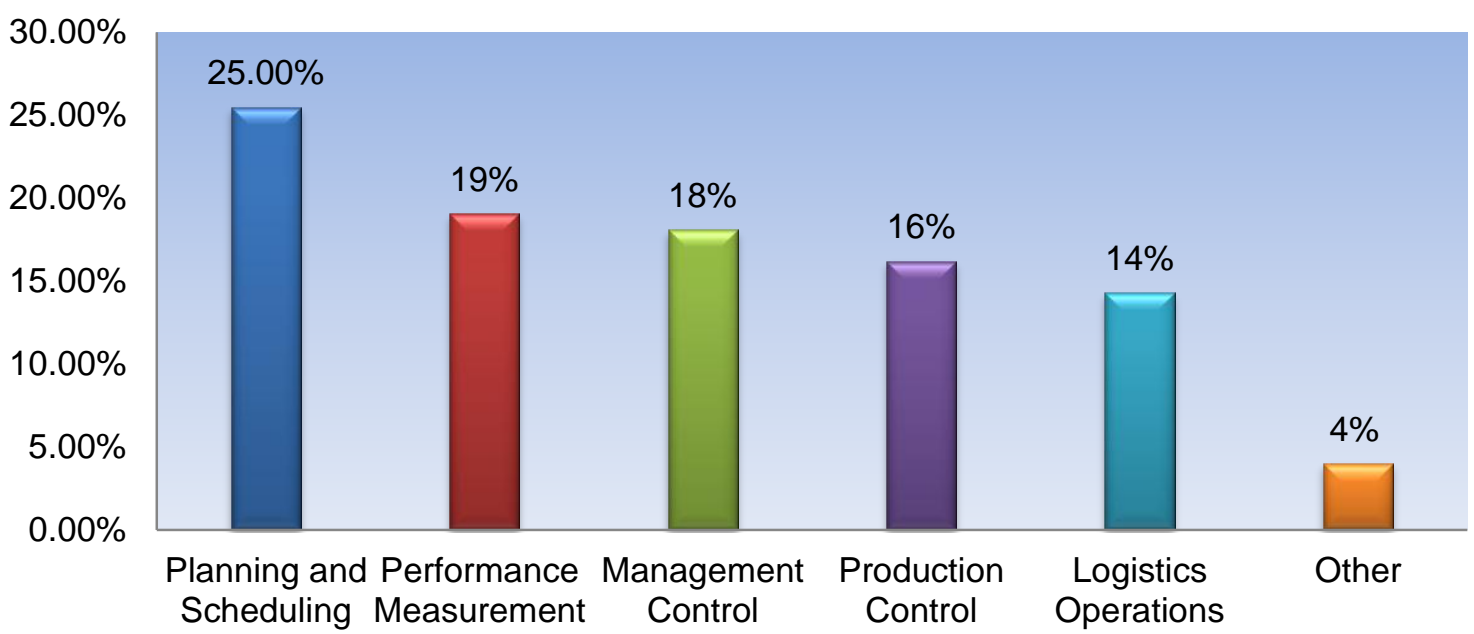

Figure 2 Areas of application of LPS within construction organisations

\section{Practitioners' Understanding to the Function of the PPC value within the LPS}

Respondents were then asked if the Percentage Plan Complete (PPC) value in LPS: (a) measures the level of utilisation of work flow (efficiency), (b) measures production planning effectiveness and work flow reliability, or (c) both of [a] and [b]. The aim of this question was to examine the respondents' awareness/understanding to the function of the PPC value when using the LPS, as a means for performance measurement. More than half of the respondents $(62.5 \%)$ mentioned that the question is not applicable to them; and only $15 \%$ of all respondents were able to answer the question correctly.

\section{Discussion}

The selection of appropriate measures has a major influence on the implementation of strategies, and is essential for the continuous development of improvement programmes (Lantelme and Formoso, 2000). That is because without the use of appropriate PMSs, it becomes very difficult for organizations to understand why poor performance continues or how improvement could be achieved (Leong and Tilley, 2008). Based on a review of a range of measurements developed to evaluate project performance, a number of process-oriented (leading) measures were selected and provided alongside other traditional (lagging) measures; to determine the techniques used by construction organisations for performance measurement. The results revealed that professionals rely heavily on results-based KPIs as opposed to process performance measures. It was also found that many organisations still depend on the experience of their managers as a means for project performance measurement.

Despite the fact that continuous improvement requires analysis of processes and devising an internal metrics for evaluating performance, only about $35 \%$ of the respondents mentioned that their organisations use their own metrics that is consistent with their business strategy. Also, process (non-financial) performance measures and LPS, which are recommended by researchers for providing means to support the successful implementation of LC, were selected by just $27 \%$ and $16 \%$ of all respondents respectively. However, when the respondents were asked to give a score out of ten (10 being the most important and 1 being the least important) to some non-financial performance measures, the mean values of three measures namely: safety, client satisfaction and quality obtained a score above 8 (most significant); and the lowest score obtained amongst all other performance measures was 7.6. These results indicated that although construction practitioners recognise the

Sarhan, S and Fox, A (2013) 'Performance measurement in the UK construction industry and its role in supporting the application of lean construction concepts', Australasian Journal of Construction Economics and Building, 13 (1) 23-35 
importance of the use of process and non-financial performance measures, it has not been properly and widely implemented in the construction industry. Most managers still make decisions just based on their experience and common sense, and on a few traditional financial measures which are no longer suitable in the existing competitive environment. These two approaches, in particular, are no longer appropriate for continuous improvement, and have been strongly criticised by many researchers.

The Last Planner System (LPS) is a production planning and control system based on lean production principles, which is developed to improve planning reliability and project performance (Gonzalez et al., 2010). It introduces the next customer into the equation through continuous and collaborative planning (Johansen and Walter, 2007; Mossman, 2009b). Through the LPS methodology, project teams commit to complete assigned tasks in a given week using functions such as: 'Look-Ahead Plan' to plan what can be done when constraints are removed, and the Percent Planned Complete (PPC) which monitors the Look-ahead Plan and requires reasons for delays which are analysed in terms of root causes (Ansell et al., 2007). Some LC practitioners refer to percentage plans complete (PPC) as a metric for commitment reliability. From results obtained, it appeared that LPS is not widely used among construction organisations. Less than half of the respondents (39\%) acknowledged that LPS is being used within their organisations; and the majority of these respondents were not aware of the full benefits of LPS and its importance in providing means for performance measurement and organisational learning. Instead, it is mainly employed by their organisations just as an activity scheduling tool. These results are consistent with the findings of Common et al. (2000).

In general there seemed to be inconsistencies in the answers of the respondents regarding how LPS is employed within their organisations, especially when it comes to its application as a means/tool for performance measurement and organisational learning (See Figures 1 and 2). Furthermore, it was found that a minority of all respondents (only 15\%) were aware of what the PPC ratio actually measures. This contradiction suggests that there is a considerable lack of awareness of the application of LPS and its role, in terms of creating conditions for decentralised control and providing a learning process at operational level (Lantelme and Formoso, 2000).

Ontological work by Rooke et al. (2003; 2004; 2007) emphasised that the most successful production management solutions are flow based ones; and that adherence to substance (results based) thinking poses a significant barrier to achieving progress in the construction industry. Thus, it could be argued here that if the overreliance of the respondents/practitioners on using results based KPIs would be classified as an example of substance (object) thinking as opposed to process performance measures - e.g. of process thinking, then accordingly it is suggested that substance thinking amongst professionals acts as a significant hidden barrier that mitigates against the successful implementation of LC. The term hidden is used by the authors to describe this sort of barrier because it has not yet been empirically demonstrated in construction research. However, this suggestion is strongly supported by a series of ontological work conducted by Rooke et al. (2003; 2004; 2007); and is linked to educational psychology work by (Itza-Ortiz et al., 2003) where it was observed that students in general tend to face difficulties in absorbing process-based theories, in contrast to more simply understood substance-based ones. Academic researchers are highly recommended to explore the root causes of this problem (adherence of practitioners to results-based solutions). One way to address this issue could possibly be achieved through investigating the role that psychology can play in the educational framework, in terms of facilitating the learning process of flow based concepts and solutions amongst students, within the construction and built environment.

Sarhan, S and Fox, A (2013) 'Performance measurement in the UK construction industry and its role in supporting the application of lean construction concepts', Australasian Journal of Construction Economics and Building, 13 (1) 23-35 


\section{Conclusions and Recommendations}

Lean construction efforts could prove to be highly rewarding for the construction industry, and could possibly lead the UK construction industry's quest to improve quality, efficiency and customer satisfaction. Several studies emphasised that the selection of appropriate measures has a major influence on the implementation and development of initiative business strategies (i.e. lean construction). Results of this study revealed that professionals rely heavily on results-based Key Performance Indicators (KPIs) as opposed to process performance measures. It was also found that many organisations still depend on the experience of their managers as a means for project performance measurement. These two approaches are not suitable for supporting the application of LC concepts and have been criticised by many researchers because they are no longer appropriate for continuous improvement.

Although, construction practitioners recognise the importance of the use of process and nonfinancial performance measures, it has not been properly and widely implemented in the UK construction industry. However, three non-financial KPIs were determined by respondents as highly important for construction organisations, namely: safety, client satisfaction and quality respectively. Hence it is important to link academic efforts with industry needs; therefore researchers are encouraged to focus their efforts on developing these three non-financial KPls identified by the study so they can be applied by organisations and their supply-chain throughout all stages of construction projects.

The study indicated that there is a limited application of Last Planner System (LPS) among UK construction organisations. Some of the respondents professed to have embraced the LPS methodology as a means for performance measurement and organisational learning; while further questioning suggested that there is a considerable lack of awareness of the application of LPS and its role, in terms of creating conditions for continuous improvement and providing a learning process at operational level.

There are very few, if any, studies that have sought to explore and understand the underlying causes of why professionals in the construction industry adhere to results-based solutions, as opposed to flow-based ones. This study identified the overreliance of the practitioners on using results-based KPIs as an example of substance (object) thinking as opposed to process performance measures - e.g. of process thinking. Accordingly, it is suggested that substance thinking amongst professionals could be considered a significant hidden barrier that militates against the successful implementation of $L C$. This suggestion is linked to the series of ontological work by Rooke et al. (2003; 2004; 2007) and supported by educational psychology work by Itza-Ortiz et al. (2003). However, further investigation and experiential research is recommended to validate this suggestion.

\section{Limitation}

This study included many of the UK's largest construction organisations, while it could be argued that most of the construction companies in the UK are micro and small. Therefore, the authors suggest that a larger and more random sample is required to generalise and validate the findings of the study.

\section{References}

Ab Rahman, M. N., Shokshok, M. A. and Abd Wahab, D. (2011) 'Barriers and benefits of total quality management Implementation in Libyan manufacturing companies', Middle-East Journal of Scientific Research, 7 (4), 619-624

Abdullah, S., Abdul-Razak, A., Abubakar, A. and Mohammad, I. S. (2009) 'Towards producing best practice in the Malaysian construction industry: The Barriers in implementing the lean construction approach', Faulty of Engineering and Geoinformation science, Universiti Teknologi, Malaysia

Sarhan, S and Fox, A (2013) 'Performance measurement in the UK construction industry and its role in supporting the application of lean construction concepts', Australasian Journal of Construction Economics and Building, 13 (1) 23-35 
Alarcon, L. F. and Serpell, A. (1996) 'Performance measuring, benchmarking, and modelling of project performance', Proceedings for the 5th International Conference of the International Group for Lean Construction (IGLC-5), The University of Birmingham, UK

Alarcón, L., Grillo, A., Freire, J. and Diethelm, S. (2001) 'Learning from collaborative benchmarking in the construction industry', Proceedings for the 9th International Conference of the International Group for Lean Construction (IGLC-9), Singapore

Alarcon, L. F., Diethelm, S. and Rojo, O. (2002) 'Collaborative implementation of lean planning systems in Chilean construction companies', Proceedings for the 10th Annual Conference of the International Group for Lean Construction, Gramado, Brazil, 6 - 8 August 2002

Andersen, B., Belay, A. M., and Amdahl Seim, E. (2012) 'Lean construction practices and its effects: A case study at St Olav's Integrated Hospital, Norway', Lean Construction Journal, 2012, 122-149

Arbulu, R., and Zabelle, T. (2006) 'Implementing Lean in Construction: How to Succeed', Proceedings for IGLC-14, Santiago, Chile

Bowen, P. A., Cattel, K. S., Hall, K. A., Edwards P. J., Pearl, R. G., (2002) 'Perceptions of Time, Cost and Quality Management on Building Projects', Australasian Journal of Construction Economics and Building, 2 (2), 48-56

Chan, A. P. C., Chan, D.W.M., Chiang, Y.H., Tang, B.S., Chan, E.H.W. and Ho, K.S.K. (2003) 'Exploring critical success factors for partnering in construction projects', Journal of Construction Engineering and Management, 130 (2), 188-198

Cheng, M., Tsai, H. and Lai, Y. (2009) 'Construction management process reengineering performance measurements', Automation in Construction, 18, 183-193

Costa, D., Formoso, C., Kagioglou, M. and Alarcón, L. (2004) 'Performance measurement systems for benchmarking in the construction industry', Proceedings for IGLC-12, Copenhagen, Denmark

Cummins, R.A. and Gullone, E. (2000) 'Why we should not use 5-point Likert scales: The case for subjective quality of life measurement', Proceedings for Second International Conference on Quality of Life in Cities (pp.74-93), Singapore: National University of Singapore

Dawood, N, Sikka, S, Marasini, R and Dean, J (2006) 'Development of key performance indicators to establish the benefits of 4D planning', In: Boyd, D (Ed) Proceedings 22nd Annual ARCOM Conference, 4-6 September 2006, Birmingham, UK, Association of Researchers in Construction Management, 709-718

Egan, J. (1998) Rethinking Construction: Report of the Construction Task Force, London: HMSO

Fraser, N. and Kelly, R. (2011) 'Applying a balanced score card approach to waste reduction KPIs in Lean construction', [Online] Available at: www.ciria.org (Accessed: July 2011)

Forbes, L. H., Ahmed, S. M. and Barcala, M. (2002) 'Adapting lean construction theory for practical application in developing countries', Proceedings of the first CIB W107 International Conference: Creating a Sustainable Construction Industry in Developing Countries, Stellenbosch, South Africa, 11-13 November

Forbes, L. H. and Ahmed, S. M. (2011) Modern Construction: Lean Project Delivery and Integrated Practices. London: CRC Press

Garnett, N., Jones, D. T. and Murray, S. (1998) 'Strategic application of lean thinking', Proceedings IGLC 98, Guaruja, Brazil

Sarhan, S and Fox, A (2013) 'Performance measurement in the UK construction industry and its role in supporting the application of lean construction concepts', Australasian Journal of Construction Economics and Building, 13 (1) 23-35 
Gonzalez, V., Alarcon, L., Maturana, S., Mundaca, F., and Bustamante, J. (2010) 'Improving planning reliability and project performance using the reliable commitment model', Journal of Construction Engineering and Management, 136 (10), 1129-1139

Hamzeh, F., Ballard, G., and Tommelien, I. (2009) 'Is the last planner system applicable to design? A case study', Proceedings of the 17th Annual Conference of the International Group for Lean Construction, IGLC 17, 13 -19 July, Taipei, Taiwan, 165-176

Itza-Ortiz, S.F., Rebello, S. and Zollman, D. (2003) 'Students' models of Newton's second law in mechanics and electromagnetism', European Journal of Physics, 25, 81-89

Johansen, E. and Walter, L. (2007) 'Lean construction: Prospects for the German construction industry'. Lean Construction Journal', 3 (1), 19-32

Kaplan, S. and Norton, P. (1992) 'The Balanced Scorecard - Measures that drive performance', Harvard Business Review, 70 (1), 47-54

Karanseh, A. and Al-Dahir, A. (2012) Impact of IT- Balanced Scorecard on financial performance: An empirical study on Jordanian banks', European Journal of Economics, Finance and Administrative Sciences, Issue 46, 54-70. Available at: http://www.eurojournals.com/EJEFAS_46_05.pdf

Keiser, PE. JD. (2012) 'Leadership and cultural change: Necessary components of a lean transformation', Proceedings $20^{\text {th }}$ Annual Conference of the International Group for Lean Construction, San Diego, USA, 18-20 July 2012

Koskela, L. (1992) 'Application of the new production philosophy to construction'. [Technical Report No. 72] CIFE, Stanford University

Lam, E., Chan, A. and Chan, D. (2007) 'Benchmarking the performance of design-build projects: Development of project success index', Benchmarking: An International Journal, 14 (5), 624-635

Lancaster, G., Dodd, S. and Williamson, P. (2004) 'Design and analysis of pilot studies: recommendations for good practice'. Journal of Evaluation in Clinical Practice, 10 (2), 307312.

Lantelme, E. M. V. and Formoso, C. T. (2000) 'Improving performance through measurement: The application of lean production and organisational learning principles', Proceedings of 8th International Conference of the International Group for Lean Construction, University of Sussex, Brighton

Leong, M. S. and Tilley, P. (2008) 'A Lean strategy to performance measurement - Reducing waste by measuring 'next' customer needs', Proceedings of 16th International Conference of the International Group for Lean Construction, Manchester, UK

Mitropoulos, P. and Howell, G. (2001) 'Performance improvement programs and lean construction', Proceedings of IGLC-9, Singapore

Moon, H., Yu, J. and Kim, C. (2007) 'Performance indicators based on TFV theory', Proceedings of IGLC-15, Michigan, USA

Mossman, A. (2009a) 'Why isn't the UK construction industry going lean With Gusto?', Lean Construction Journal, 5 (1), 24-36.

Mossman, A. (2009b) 'Creating value: a sufficient way to eliminate waste in lean design and lean production', Lean Construction Journal, 5, 13 - 23.

Neely, A., Mills, J., Platts, K., Gregory, M. and Richards, H. (1996) 'Performance measurement system design: Should process based approaches be adopted?', Int. J. Production Economics, 46-47, 423-431.

Nudurupati, S., Arshad, T. and Turner, T. (2007) 'Performance measurement in the construction industry: An action case investigating manufacturing methodologies', Computers in Industry, 58, 667-676.

Sarhan, S and Fox, A (2013) 'Performance measurement in the UK construction industry and its role in supporting the application of lean construction concepts', Australasian Journal of Construction Economics and Building, 13 (1) 23-35 
Olatunji, J. (2008) 'Lean-in-Nigerian construction: state, barriers, strategies and "go togemba" approach', Proceedings 16th Annual Conference of the International Group for Lean Construction. Manchester, UK

Rooke, J., Seymour, D. and Fellows, R. (2003) 'The claims culture; A Taxonomy of attitudes in the industry', Construction Management and Economics, 21 (2), 167-174

Rooke, J., Seymour, D. and Fellows, R. (2004) 'Planning for claims: An ethnography of industry culture', Construction Management and Economics, 22 (6), 655-662

Rooke, J. A., Koskela, L. and Seymour, D. (2007) 'Producing things or production flows? Ontological assumptions in the thinking of managers and professionals in construction', Construction Management and Economics, 25 (10), 1077-1085

Sarhan, S. and Fox, A. (2012) 'Trends and challenges to the development of a lean culture among UK construction organisations', Proceedings for the 20th Annual Conference of the IGLC, 1151-1160, San Diego, USA, 18-20 July 2012; Available at: http://iglc.net/?page id=277

Senaratne, S. and Wijesiri, D. (2008) 'Lean Construction as a Strategic Option: Testing its Suitability and Acceptability in Sri Lanka', Lean Construction Journal, 5 (1), 34-48

Sikka, S., Dawood, N., Marasini, R. and Dean, J. (2006) 'Identification and development of key performance indicators to establish the value of 4D planning', ARCOM Doctoral Workshop on Emerging Technologies in Construction, School of the Built Environment, University of Salford: 10 November, 2006.

Suwignjo, P., Bititci, U. S. and Carrie, A. S. (2000) 'Quantitative models for performance measurement system'. Int. J. Production Economics, 64, 231-241

Swain, B. and Mossman, A. (2003) 'Smooth and Lean - Hathaway Roofing Case', Quality World, 29 (3), 27-30

Takim, R. and Akintoye, A. (2002) 'Performance indicators for successful construction project performance', 18th Annual ARCOM Conference, University of Northumbria: 2-4 September 2002, 545-555

Terry, A. and Smith, S. (2011) Build Lean: Transforming construction using lean thinking. London: CIRIA

The KPI Working Group (2000) 'KPI Report for the Minister for Construction'. [Online], Available at: www.bis.gov.uk/files/file16441.pdf (Accessed: 15 July 2011)

$\mathrm{Wu}$, P. and Low S. P., (2011) 'Lean production, value chain and sustainability in precast concrete factory - a case study in Singapore', Lean Construction Journal, 92-109 